\title{
70. A Quantitative Study of the Perceptibility of Sound Waning in Modifying Sound Characteristics.
}

By Ryûzaburô TAguti.

(Comın. by A. TanakanaTr, M. T. A., Dec. 12, 1946.)

Equation of a sound emanating from a single source may be represented by

$$
F^{*}=e^{\prime}-a t \sum_{i=1}^{A} \mathfrak{A}_{i} \sin \left(i \omega t+\mu_{i}\right)
$$

and the equation of sounds emanating from many sources such as symphony music or noise in general may be represented as (2)

$$
F=\sum_{l=1}^{C} \sum_{k=1}^{B l} \sum_{i=1}^{A l k} a_{i, l k} e^{-a l k t} \sin \left(i \omega_{l} t+\phi_{i, l k}\right)
$$

$\mathfrak{A}$ and $a$...Amplitude.

w......angular frequency.

r.......phase.

a......indix of sound waning. (indix of the fourth sense of audibility.)

$i$......number of harmonics giving sound color. $\left(1,2,3 \ldots \mathrm{A}_{1 k}\right)$

$k \ldots . .$. number of sources in unison $\left(1,2,3, \ldots \mathrm{B}_{1}\right)$

$l$......number of sources not in unison $(1,2,3, \ldots \mathrm{C})$

$$
A \longrightarrow \infty, B \longrightarrow \text { finite, } C \longrightarrow \infty
$$

In order to settle the important question how far the ear can distinguish different degrees of waning factor or indix the following experiments were carried. Pitch and intensity of sound which depend on $\omega$ and $a$ are already wellknown. But color and waning (damping) have not been yet subject to quantitative research, and arrived at definite result.

A preliminary research was made on three graduates of the Musical Academy to find how far the ear can estimate the duration of a single sound given by a single touch of any of a piano key differently damped by controled of the pedal. The result was satisfactory within $80 \%$ perceptibility, after a week's practice.

A special standard of sound wane was constructed of an iron plate hav: ing a pure tone of 435 hertz, provided with a damper with an adjustable scale corresponding to the values of $\alpha 0.2,0.4 \ldots \ldots .2 .0$ in the equations (1) and (2). carefully guaged by comparing with oscillograph records. Fig. (1) gives the aelative intensity of sound, and Fig. (2) their logarithmic values.

The observers or examinee are to memorize these scales by listening to 
the standard in action. The three observers abovementioned, after a practice of a month and half, were able to estimate by ear observation the scales of waning within 0.1 under various conditions expressed in the equations (1) and (2) above. That is to say, the sound wane is now shown to be one of the sound charactrics among those known as pitch, color, intensity.

The research was aimed to be continued further, when all the instrumenst together with the experimental data and minutes were destroyed by the air raid of 1945.

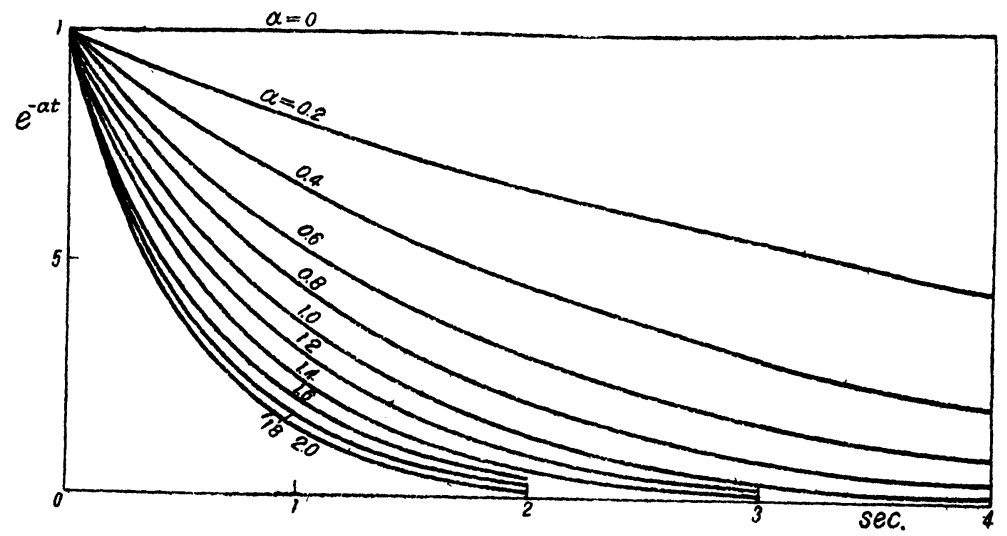

Fig. 1

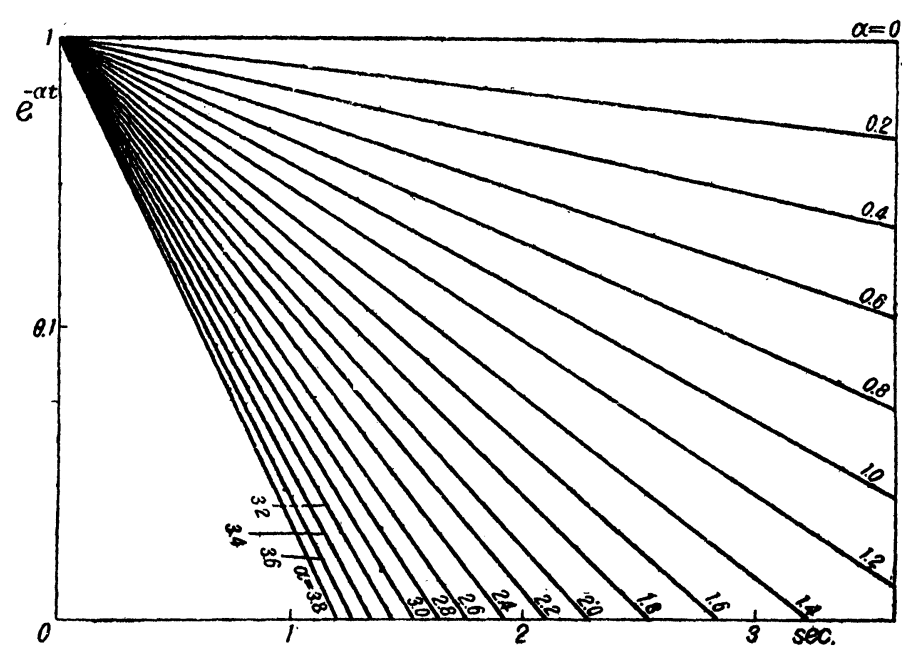

Fig. 2 